\title{
Trigger point dry needling for the treatment of myofascial pain syndrome: current perspectives within a pain neuroscience paradigm
}

This article was published in the following Dove Press journal:

Journal of Pain Research

\author{
César Fernández-de-Las- \\ Peñas ${ }^{1,2}$ \\ Jo $\mathrm{Nijs}^{3,4}$
}

'Department of Physical Therapy, Occupational Therapy, Rehabilitation and Physical Medicine, Universidad Rey Juan Carlos, Alcorcón, Madrid, Spain;

${ }^{2}$ Cátedra de Investigación y Docencia en Fisioterapia: Terapia Manual y Punción

Seca, Universidad Rey Juan Carlos, Alcorcón, Madrid, Spain; ${ }^{3}$ Faculty of Physical Education and Physiotherapy, Department of Physiotherapy, Human Physiology and Anatomy, Vrije Universiteit Brussel, Brussels, Belgium; ${ }^{4}$ Pain in Motion International Research Group, Vrije Universiteit Brussel, Brussels, Belgium
Correspondence: César Fernández-deLas-Peñas

Departamento de Fisioterapia, Facultad de Ciencias de la Salud, Universidad Rey Juan Carlos, Avenida de Atenas $s / \mathrm{n}$, Alcorcón 28922, Madrid, Spain

Tel $+349 \mid 4888884$

Fax +3 49| 4888957

Email cesar.fernandez@urjc.es

\begin{abstract}
Myofascial pain syndrome is a pain condition characterized by the presence of trigger points. Current evidence, mostly experimental studies, clearly supports a role of trigger points on peripheral and central sensitization since they are able to contribute to sensitization of peripheral nociceptors, spinal dorsal horn neurons, and the brainstem. Several interventions are proposed for treating trigger points, dry needling being one of the most commonly used by clinicians. There is no consensus on the clinical application of trigger point dry needling: some authors propose that local twitch responses should be elicited during the needling intervention to be effective, whereas others do not. The application of trigger point dry needling is able to reduce the excitability of the central nervous system by reducing peripheral nociception associated to the trigger point, by reducing dorsal horn neuron activity, and by modulating pain-related brainstem areas. However, the effects are mainly observed in the short-term, and effect sizes are moderateto small. Therefore, the current review proposes that the application of trigger point dry needling should be integrated into current pain neuroscience paradigm by combining its application with pain neuroscience education, graded exercise and manual therapy. Additionally, patient's expectations, beliefs, previous experiences and patient-clinician interaction should be considered when integrating trigger point dry needling into a comprehensive treatment approach.
\end{abstract}

Keywords: trigger point, dry needling, sensitization, chronic pain

\section{Myofascial pain syndrome and trigger points}

The International Association for the Study of Pain (IASP) recognizes that myofascial pain syndrome is a common source of musculoskeletal pain. ${ }^{1}$ Myofascial pain syndrome is a pain condition characterized by trigger points (TrPs). Although different definitions of TrPs are used among the different health care professions, the most commonly accepted definition maintains that a:

myofascial $\operatorname{TrP}$ is a hyperirritable spot within a taut band of skeletal muscle that is painful on compression, stretch, overload, or contraction of the tissue which usually responds with a referred pain that is perceived distant from the spot. ${ }^{2}$

Myofascial TrPs can be clinically classified as either active or latent. Originally, Simons et al defined an active TrP as:

a myofascial $\mathrm{TrP}$ that causes a clinical pain complaint. It is always tender, prevents full lengthening of the muscle, weakens the muscle, refers a patient-recognized pain 
on direct compression, mediates a local twitch response of muscle fibers when stimulated. ${ }^{2}$

Similarly, a latent $\operatorname{TrP}$ was defined by Simons et al as "a myofascial $\operatorname{TrP}$ that is clinically quiescent with respect to spontaneous pain; it is painful only when palpated". ${ }^{2}$ Both active and latent TrPs induce referred pain sensations and can also provoke autonomic phenomena in their pain referral zone. A recent Delphi study has proposed the term "referred sensation" instead of referred pain since TrP-associated symptoms may include different sensory sensations, ie, deep pain, distant pain, dull ache, tingling, burning sensation, and not just pain. ${ }^{3}$ In addition, a new definition of active $\operatorname{TrP}$ was proposed:

active TrPs are those TrPs that upon stimulation reproduce any symptom experienced by a patient, partially or completely, and whereby the reproduced symptom is recognized as a familiar experience by the patient. ${ }^{3}$

The referred sensation elicited by active TrPs has been able to reproduce the symptoms of a variety of chronic pain disorders, eg, tension-type headache, ${ }^{4}$ migraine, ${ }^{5}$ temporomandibular pain, ${ }^{6}$ mechanical neck pain, ${ }^{7}$ whiplashassociated neck pain, ${ }^{8}$ shoulder pain, ${ }^{9}$ lateral epicondylalgia $^{10}$ or low back pain. ${ }^{11}$ All these studies reported that latent TrPs were also found in nonsymptomatic healthy people. In fact, the meta-analysis conducted by Chiarotto et al observed that latent $\operatorname{TrPs}$ were not consistently more prevalent in people with spinal pain disorders than in healthy controls. ${ }^{12}$

Muscle TrPs are associated with both sensory and motor symptoms. For instance, active and latent $\operatorname{TrP}$ areas exhibit altered chemical milieus as compared to non- $\operatorname{TrP}$ areas. ${ }^{13,14}$ These local biochemical changes, including increased availability of pro-inflammatory substances such as substance P, IL-1 $\beta$ and tumor necrosis factor (TNF)- $\alpha$, activate muscle nociceptors potentially contributing to peripheral mechanisms by sensitizing nociceptive nerve endings. ${ }^{15}$ Other studies have reported that TrPs also sensitize non-nociceptive large-diameter myelinated afferents nerve endings. ${ }^{16,17}$ These studies support the presence of nociceptive and non-nociceptive pain sensitivity in the $\operatorname{TrP}$ area and confirm that TrPs are a focus of peripheral sensitization able to sensitize spinal and supraspinal neurons. This process is highly relevant for musculoskeletal pain conditions since it has been observed that TrP spinal cord connections are more effective in inducing neuroplastic changes in the dorsal horn neurons than non-
TrP tissues and they are connected to a greater number of nociceptive neurons. ${ }^{18}$ Finally, the study by Xie et al has recently reported that individuals with chronic myofascial pain exhibited microstructural abnormalities in those brain areas involved in the dynamic pain connectome (previously known as the "pain matrix"), eg, anterior cingulate cortex or prefrontal cortex. ${ }^{19}$

Importantly, and many times ignored by several clinicians, TrPs also contribute to motor impairments including altered muscle activation patterns, ${ }^{20}$ accelerated muscle fatigability, ${ }^{21}$ or increased co-antagonist activation. ${ }^{22}$ Therefore, there is evidence supporting that $\operatorname{TrPs}$ can contribute to motor and sensory impairments observed in individuals with chronic pain.

\section{Trigger point dry needling Definition}

Several needling treatments are proposed for treatment of myofascial pain syndrome. In fact, two different needling applications can be used to inactivate TrP: wet needling (injections) or dry needling. ${ }^{23}$ Wet needling refers to the injection of a substance into the $\operatorname{TrP}$ area through a hypodermic needle with a beveled, cutting edge; whereas dry needling refers to the insertion of a solid filiform needle into a $\operatorname{TrP}$ without the introduction of any substance. In addition, dry needling can be also combined with electrical current giving other modalities such as electrical dry needling or percutaneous electrolysis.

Among needling therapies, trigger point dry needling (TrP-DN) is probably the most popular, at least in some health care professions. ${ }^{24}$ The American Physical Therapy Association (APTA) defined dry needling as a:

skilled intervention using a thin filiform needle to penetrate the skin that stimulates myofascial $\mathrm{TrPs}$, musculature and connective tissue for the management of neuromusculoskeletal disorders. ${ }^{25}$

The Australian Society of Acupuncture Physiotherapists described dry needling as :

rapid, short term needling to altered or dysfunctional tissues in order to improve or restore function. This may include needling of myofascial TrPs, periosteum, and connective tissues. It may be performed with an acupuncture needle or any needle without the injection of a fluid. ${ }^{26}$

Since TrP-DN and injections, either anesthetics or botulinum toxin, are probably the needling therapies most commonly used for the treatment of myofascial pain whereas 
acupuncture is also used for treating other medical conditions, the current paper discusses the rationale for clinical application of TrP-DN for myofascial pain.

\section{Clinical application: the local twitch response}

Probably the most expanded needling approach used for the management of TrPs is the one described by Hong: ${ }^{27}$ the "fast in, fast out" method of needling of a TrP. The technique consists of inserting the needle into the TrP until a first local twitch response is obtained. A local twitch response is defined as brief and sudden contraction of a $\operatorname{TrP}$ taut band with needle insertion which is suggested to be a spinal cord reflex linked to the sensitivity of dysfunctional motor endplates. Once a first local twitch response is obtained, the needle is moved up and down, with no rotations, to get more local twitch responses. Hong showed that when TrP needle penetration produced local twitch responses, it was much more likely to result in subsequent pain relief than needle penetration that did not elicit local twitch responses independently of the introduction or not of any substance. This author originally proposed that local twitch responses should be obtained during the application of TrP-DN to be effective. ${ }^{27}$

However, the number of local twitch responses needed to obtain a positive outcome has always been a topic of debate. No clinical differences in pain intensity improvement have recently been found, depending on the number of local twitch responses (one, two, three or six) elicited during the application of TrP-DN in the upper trapezius muscle in individuals with mechanical neck pain. ${ }^{28}$ Similarly, Koppenhaver et al also found no differences in pain and function changes between individuals with low back pain experiencing local twitch response during dry needling of the lumbar multifidus and those not experiencing local twitch responses. ${ }^{29}$ Discrepancies in the published studies lead some authors to question the need of eliciting local twitch responses during the application of needling therapies. ${ }^{30}$

This is an interesting topic since many patients perceive the local twitch response as an uncomfortable sensation during the treatment. Therefore, prior to the application of any needle approach, the patient should be warned that needle contacting with a TrP may cause the muscle to twitch or produce a flash of distant pain. Interestingly, some clinicians propose the use of the referred pain, in addition to or instead of the local twitch response, during the application of TrP-DN. If a pain referral with or without a local twitch response is elicited during the clinical examination of a $\operatorname{TrP}$ prior to the application of needling therapies, then one or both signs can be also elicited and monitored during the needling procedure. A recent study has observed that application of TrP-DN was able to elicit in an easier manner the referred pain of a muscle, in this study the infraspinatus muscle, than manual palpation. ${ }^{31}$ In this situation, the clinician can confirm the pain referral of a particular muscle and the patient can connect the symptoms if the $\operatorname{TrP}$ in that muscle reproduces the symptom of the patient. However, no scientific evidence for this hypothesis is available.

\section{Adverse events}

Clinicians must follow guidelines for safe dry needling practice, which can be consulted elsewhere. ${ }^{32}$ Independently of the needling therapy used for treatment, the needle should be considered as an extension of the clinician's finger; therefore, the clinician should properly identify the $\operatorname{TrP}$ area before inserting the tip of the needle. It is important to consider that proper application of needling therapies needs deep knowledge of human anatomy and patient's clinical status for minimizing adverse events. ${ }^{33,34}$ In fact, muscles that are deep or in close proximity to neurovascular structures may be accessed using ultrasound guidance during the needling intervention. Although the risk of adverse events is small when an experienced clinician applies needling therapies, eg, acupuncture ${ }^{35}$ or TrP$\mathrm{DN},{ }^{36}$ for the management of myofascial pain; cases of significant adverse events including pneumothorax, ${ }^{37}$ puncturing the stomach $^{38}$ cardiac tamponade, ${ }^{39}$ epidural hematoma, ${ }^{40}$ hemiplegia ${ }^{41}$ or infection ${ }^{42}$ have been documented. Therefore, although needling therapies seem to be safe when properly applied, it cannot be implied that there is no risk of potentially serious complication.

\section{Post-needling induced-pain or post- needling soreness}

The American Physical Therapy Association recommends to advise the patients about the presence of soreness after the application of TrP-DN, this is called, post-needling induced-pain or post-needling soreness. ${ }^{43}$ Post-needling induced-pain or soreness is probably the most common minor adverse event and it can be associated with possible reluctance to receive further needling therapy by generating patient dissatisfaction and reduction in treatment adherence. ${ }^{44}$ It is assumed that post-needling soreness is thought to be a consequence of the neuromuscular damage generated by the consecutive needling insertions into the 
muscle. ${ }^{45}$ This hypothesis has been supported by a recent study showing that muscle damage identified by magnetic resonance imaging after the application of dry needling over the gastrocnemius muscle was associated withpostneedling induced-pain. ${ }^{46}$ Other authors have associated the presence of post-needling to the number of local twitch responses elicited during the needling therapy. ${ }^{47}$

Clinicians use several treatment modalities after the application of TrP-DN for reducing post-needling inducedpain. For instance, postural education, activity modification, self-stretch, therapeutic exercise, or neuromotor re-training following TrP-DN could be considered as an integral part of the treatment. The inclusion of active therapies after the application of passive modalities such as TrP-DN could establish the patient's conscious awareness of normal function in that muscle while reprogramming the brainstem to incorporate the newly restored full-range capability of the muscle into the patient's daily activities; although this hypothesis needs confirmation. Clinicians could use contemporary pain sciences to prevent or reduce post-needling induced-pain or soreness (ie by educating patients about pain as a way to diminish expectations of adverse events.

Nevertheless, it is commonly seen in clinical practice that most patients usually recover from post-needling induced-pain/soreness between 48 and 72 hours after the intervention. This clinical observation has been confirmed in recent studies investigating the effects of some postneedling techniques, eg, spray andstretch, ${ }^{48}$ ischemic compression, ${ }^{49}$ or low-load eccentric exercise. ${ }^{50}$ All these studies found that these interventions were effective for decreasing post-needling induced pain/soreness 12 hours after TrP-DN application, but at 48 and 72 hours after, all patients were recovered from post-needling induced-pain independent of the post-needling intervention.

\section{Effectiveness of trigger point dry needling}

It was 40 years ago when the first paper reporting the use of dry needling for the management of myofascial pain was published. ${ }^{51}$ In recentyears, there has been an increase in the number of clinical trials and systematic reviews investigating the effectiveness of TrP-DN; however, there is no consensus regarding the superiority of TrP-DN or needling injections. Two meta-analyses have demonstrated that both wet needling (lidocaine injections) and TrP-DN seem to be similarly effective for neck/shoulder myofascial pain without clear differences between both needling therapies. ${ }^{52,53}$ The meta-analysis by Ong and Claydon included one dry needling vs placebo study and for dry needling vs lidocaine infusion studies, ${ }^{52}$ whereas Liu et al only analyzed short- and medium-term effects. ${ }^{53}$ Therefore, we will review in the current text the most updated evidence related to TrP-DN for the management of chronic pain syndromes.

In 2016, the Canadian Agency for Drugs and Technologies in Health has accepted the use of dry needling in the public health system, ${ }^{54}$ based on the effectiveness of TrP-DN for the management of musculoskeletal pain syndromes in the upper ${ }^{55}$ and lower ${ }^{56}$ quadrants currently supported by different systematic reviews and meta-analysis; however, it should be recognized that most evidence refers to short (one month) or mid (3 months), but not long-term (6 months) effects and inadequate blinding procedures could lead to exaggerated effects in dry needling trials. ${ }^{57}$

A recent meta-analysis investigating the effects of dry needling for the management of patients with temporomandibular disorders concluded that dry needling was better than other interventions for reducing pain intensity (SMD: $-0.74,95 \% \mathrm{CI}:-1.25$ to -0.22 ) as well as better than sham therapy for increasing pressure pain thresholds (SMD: $0.56,0.31$ to 0.81$).{ }^{58}$ This meta-analysis included seven trials, mostly with high risk of bias, and also reported discrepancy among dry needling interventions, suggesting that current evidence is still inconclusive. ${ }^{58}$ The review conducted by France et al found poor evidence supporting any meaningful effect of dry needling for the management of tension type headache; however, there was a small number of studies $(\mathrm{N}=3)$, some of them did not report the presence of TrPs (acupuncture), and only one study reported on headache frequency or intensity. ${ }^{59}$

The meta-analysis conducted by Hall et al investigated the effectiveness of dry needling on shoulder pain. ${ }^{60}$ It included 11 trials and concluded that there is littleevidence supporting the application of dry needling in the shoulder region for treating patients with upper extremity pain or dysfunction; however, the results come from a combination of studies including patients with musculoskeletal (shoulder pain) but also neurological (stroke) conditions; ${ }^{60}$ therefore, these results should be considered with caution at this stage.

A PRISMA meta-analysis conducted in individuals with low back pain showed that dry needling was more effective than acupuncture for reducing pain intensity (SMD $-0.96,-1.80$ to -0.12 ) and related-disability (SMD $-0.63,-0.99$ to -0.26 ) after treatment, but 
similarly effective at longer follow-up (SMD -0.10 , -0.65 to 0.45$){ }^{61}$ Similarly, real dry needling was also superior to sham needling for improving pain (SMD $-2.74,-3.77$ to -1.71 ) and related-disability (SMD $-1.70,-2.59$ to -0.81$)$ at post-intervention. ${ }^{61}$

The effectiveness of dry needling for the management of patients with plantar heel pain has been also investigated in a recent meta-analysis including seven clinical trials. ${ }^{62} \mathrm{He}$ and Ma concluded that TrP-DN was effective for reducing pain intensity (SMD $-15.5,-19.48$ to -11.53 ) compared with a control intervention. Importantly, TrPDN was not associated with a higher incidence of adverse events (RR: $1.89,0.38$ to 9.39) than control treatment. ${ }^{62}$

An interesting meta-analysis conducted by Gattie et al found low to moderate evidence suggesting that dry needling, when applied by physical therapists, is superior to no treatment or sham-needling, but equally effective as other physical therapy interventions for short- and mid-term follow-ups for musculoskeletal pain conditions. ${ }^{63}$ These results support the application of clinical reasoning needed for the application of TrP-DN in patients with chronic pain conditions.

There is also evidence from high quality randomized clinical trials not included in the abovementioned reviews deserving some discussion. A randomized clinical trial investigating the long-term effects of TrP-DN for subacromial pain syndrome found that TrP-DN combined with exercise was more effective than exercise alone for improving disability at 6 months (between-groups difference $-23.6,-28.9$ to 18.3$)$ and 12 months $(-13.9,-17.5$ to -10.3$) .{ }^{64}$ No between-groupdifferences in pain were observed. ${ }^{64}$ Interestingly, the cost-effectiveness analysis of this clinical trial reported that TrP-DN combined with exercise was less costly (mean difference cost/patient: €517.34) than exercise alone supporting the effectiveness of TrP-DN. ${ }^{65}$

Nevertheless, it should be recognized that TrP-DN has not been found to be effective for musculoskeletal pain conditions of the knee. Espí-López et al observed that the inclusion of TrP-DN into a manual therapy and exercise program did not result in better outcomes for pain and disability in people with patellofemoral pain syndrome. ${ }^{66}$ Similarly, the application of TrP-DN combined with exercise was equally effective than exercise alone for improving pain and function in adults with knee osteoarthritis. ${ }^{67}$ Discrepancies maybe related to differences in the needling technique, clinical reasoning for applying the intervention, patient population, $\operatorname{TrP}$ diagnostic criteria, formation of clinicians applying the technique, among others. Additionally, it is also possible that in some areas, such as the knee, the application of dry needling should be combined with other interventions, eg, electrical current (electrical dry needling) as recently reported in a multicenter randomized clinical trial. ${ }^{68}$

\section{Mechanisms underlying trigger point needling therapy}

The underlying mechanisms by which TrP-DN exerts its therapeutic effects are not fully understood and both mechanical and neurophysiological mechanisms have been proposed. ${ }^{65}$ Both therapeutic mechanisms target the motor and sensitive component of the $\operatorname{TrP}$ based on the integrated hypothesis. ${ }^{69}$

From a mechanical viewpoint, it has been suggested that TrP-DN is able to disrupt the dysfunctional end plates, to increase of sarcomere length, and to reduce the overlapping between actin and myosin filaments. ${ }^{70}$ The first mechanical effect was supported by the hypothesis that TrP-DN is able to reduce endplate noise characteristicof the TrP area. ${ }^{71}$ Some studies have confirmed that TrP-DN decreases the amplitude and frequency of end plate noise and end plate spike, ie, typical sponteneous electrical activity features of $\mathrm{TrPs}$, decreases the acetylcholine levels ${ }^{72,73}$ and the neuromuscular junction response. ${ }^{74} \mathrm{~A}$ decrease in end plate noise and end plate spike after the application of TrP-DN would support an effect on the motor end plate. The animal study by Domingo et al found that needle insertions induce a neuromuscular dagame supporting an effect of TrP-DN on the motor end plate. ${ }^{45}$ Importantly, its seems that reduction in sponteneous electrical activity was associated to the presence of local twitch responses during the needling procedure, supporting the relevance of local twitch responses during application of dry needling. ${ }^{71,72}$ The potential decrease in acetylcholine levels could lead to the second and third mechanical effects. In fact, the increase in muscle blood flow and oxygenation observed after TrP-DN would support a reduction of sarcomere contracture. ${ }^{75}$ Therefore, it seems that dry needling exerts several mechanical effects on the $\operatorname{TrP}$ area, which potentially may initiate a cascade of neurophysiological mechanisms. ${ }^{69}$

From a neurophysiological viewpoint, TrP-DN may reduce both peripheral and central sensitization by removing the source of peripheral nociception ( $\mathrm{TrP}$ area), by modulating spinal dorsal horn activity, and by activating central inhibitory pain pathways. ${ }^{76}$ It is known that the insertion of a needle into the body elicits different natural 
neurophysiological mechanisms like stimulation of the A $\delta$ and $\mathrm{C}$ fibers or activation of cortical brain areas, but these effects will be not discussed as they are common to needle therapies, eg, acupuncture, and not just associated to TrPDN. $^{77}$

There is evidence supporting that TrP-DN is able to mediate at different levels of the nervous system. ${ }^{78}$ The first mechanism is the reduction of peripheral nociception. The studies by Shah et al observed an immediate drop in the peripheral concentrations of neurotransmitters, including calcitonin gene related peptide or substance $\mathrm{P}$ and also several cytokines and interleukins within the extracellular fluid of the TrP after needle insertion. ${ }^{14,15}$ Hsieh et al confirmed that dry needling modulated the chemical mediators associated with pain and inflammation by reporting and increase in $\beta$-endorphin and TNF- $\alpha$ levels and a decrease of substance $\mathrm{P}$ levels after the application of dry needling in an animal model. ${ }^{79}$ The reduction of peripheral nociception would lead to the second step, the decrease of spinal dorsal horn neuron activity. A spinal cord mechanism is supported by the studies reporting remote effects of TrP-DN in those muscles anatomically located in the referred pain area of the needled musculature. This remote effect is bidirectional, needling a proximal muscle leads to a remote effect on a distal related muscle $^{80}$ and needling of a distal muscle leads to a remote effect on a proximal related muscle. ${ }^{81}$ In fact, Hsieh et al ${ }^{82}$ found that the remote effect of dry needling depends on an intact afferent pathway from the needled site to the spinal cord and a normal dorsal horn neurons function at those innervation levels of the related muscle. More importantly, the remote effect of TrP-DN involves the reduction of substance $P$ levels in spinal superficial laminas of the dorsal horn. ${ }^{83}$ These spinal cord mechanisms would explain anti-nociceptive effects elicited by dry needling ${ }^{84}$ and the bilateral responses elicited during unilateral needling insertion. ${ }^{85}$

Finally, a decrease of dorsal horn neuron activity leads to the third step, the brainstem. There is evidence supporting that needling therapies activate cortical brain areas involved in sensorimotor processing, including insula, thalamus, anterior cingulate cortex or somatosensory cortex, but also deactivate the brain regions involved in limbicparalimbic neocortical network, such as the medial prefrontal cortex, caudate, amygdala, or posterior cingulate cortex. ${ }^{86}$ More particularly, Niddam et al reported that pain following the insertion of a needle into a TrP area, combined with electrical stimulation, is mediated through the periaqueductal gray substance in the brainstem, suggesting that TrP-DN, via stimulation of the nociceptive fibers, may activate enkephalinergic inhibitory dorsal horn interneurons. ${ }^{87}$ In conclusion, current evidence suggests that TrP-DN involves peripheral, spinal, and supraspinal mechanisms underlying its effects.

\section{Integrating contemporary pain science and trigger point needling therapy}

When providing dry needling to patients having chronic pain, therapists are advised to integrate contemporary pain neurosciences when providing the treatment. This implies applying evidence-based recommendations; therefore, TrP-DN can be part of, but should never be, the only treatment plan for individuals with chronic pain. Per evidence-based recommendations, a comprehensive management program for chronic pain patients should include neuroscience pain education, ${ }^{88}$ exercise programs, ${ }^{89}$ self-management (including graded activity), ${ }^{90}$ stress management (psychological), ${ }^{91}$ sleep management, ${ }^{92}$ and other individuallytailored aspects of self-management. Passive treatments, such as needling therapies or manual therapies, can improve pain and function inthe short-term (small-moderate effect sizes), but they should be integrated in a comprehensive pain management approach to contribute to prolonged/long-term effects with medium to large effect sizes. The pitfall when doing this, relates to the message that such passive intervention gives (is perceived) to the patient. The message may strengthen the common patient's biomedical view that (more) pain relates to (more) tissue damage, which is a typical maladaptive belief reducing long-term recovery and patient's independence. Indeed, the traditional model of pain assumes that there is a direct association between the amount of local tissue damage and the level of pain experienced by the patient. It advocates a "find it and fix it" therapeutic model imparting patients' dependence on passive interventions, eg, dry needling or hands-on manual therapy. ${ }^{93}$

Here we provide a proposal by integration of the contemporary pain sciences to prevent such "situation" of needling treatment for chronic pain patients. Contemporary pain sciences have broadened our understanding of chronic pain towards a complex biopsychosocial problem. Pain science has advanced our understanding about pain, including the role of central nervous system sensitization in the presence and amplification of (persistent) pain experiences. Central sensitization can be defined 
as "an amplification of neural signaling within the central nervous system that elicits pain hypersensitivity" and as "an increased responsiveness of nociceptive neurons in the central nervous system to their normal or subthreshold afferent input". 94 Many people with chronic pain lack a clear origin of nociceptive input (or the clinician is not able to properly identify it), or this input is not severe enough to explain the experienced pain severity, related disability, and other symptoms. This may likely be the case for myofascial TrPs, where they potentially contribute to the pain experience and can serve as a bottom-up input facilitating sensitization of nociceptive pathway, although TrPs are not clearly associated to tissue damage.

Pain arising from altered nociception despite no clear evidence of actual or threatened tissue damage causing the activation of peripheral nociceptors or evidence for disease or lesion of the somatosensory system causing the pain (eg, central sensitization) is labelled now as "nociplastic pain" by the International Association for the Study of Pain. ${ }^{95}$ Central nervous system sensitization is a well-established feature in many chronic pain conditions; hence, in such pain conditions it remains to be elucidated whether TrPs represent symptoms of central nervous system sensitization (consequence of), or contribute to its process. This topic has been previously reviewed by Fernández-de-las-Peñas and Dommerholt. ${ }^{96}$ There is some evidence from experimental studies supporting that TrPs can be a peripheral source of nociception in some cases, and if so, they may act as ongoing nociceptive stimuli contributing to pain propagation and widespread pain observed in chronic pain conditions exhibiting central sensitization, and that appropriate treatment reduces central sensitization. ${ }^{96}$ Nevertheless, there is also evidence suggesting that central sensitization can also promote TrP activity, creating a bidirectional interaction.

Understanding central nervous system sensitization and its role in relation to chronic pain sustainment should not be interpreted in a catastrophic way: when treatment for chronic pain takes central nervous system sensitization into account, it can improve substantially alongside the clinical improvement (in terms of pain severity and functional improvement) in several conditions, eg, chronic spinal pain ${ }^{97}$ and carpal tunnel syndrome. ${ }^{98}$ Cardinal to taking central nervous system sensitization into account when treating individuals having chronic pain, is not relying on short-term changes in pain. Understanding central nervous system sensitization implies that pain is no longer a reliable messenger. Moreover, adapting to variances in pain will reward the brain in producing pain. This idea is broadly acknowledged and implemented among health care practitioners applying exercise and physical activity interventions to patients with chronic pain and central nervous system sensitization but applies to needling therapies or any other passive treatment as well.

\section{How to deal with pain in clinical practice}

Applying contemporary pain neuroscience when providing TrP-DN can be conducted as follows. First, pain neuroscience education can be applied before application of dry needling, although this could be modified depending on the type of patient. This allows patients to gain a broader understanding of their pain problem, including the role of neurophysiological (eg, central nervous system sensitization), psychological, social and environmental factors on top of possible biomedical factors such as TrPs areas in the muscle tissue. Pain neuroscience education typically decreases the threat value of pain, diminishes catastrophic thinking about pain, and facilitates a more active coping strategy. ${ }^{88}$ However, clinicians may encounter several practical problems when trying to combine pain neuroscience education and dry needling in the context of a patient with chronic pain. That includes occurrence of contradictory messages between the two interventions since TrP-DN is usually perceived as a "painful" intervention by the patient. There is literature suggesting that a brief painful needle insertion (stimulus) is insufficient to induce or maintain central sensitization since the response within the pain neuromatrix is strongly influenced by the context in which the painful stimulus appears and within the context of a therapeutic encounter. In such a scenario, needling therapies may trigger a conditioned pain modulation response by activating an endogenous pain inhibitory mechanism that inhibits nociceptive pain processing. ${ }^{99}$

Second, once the patients realize that the somewhat uncomfortable stimulus of the TrP-DN intervention has the potential to reduce or even eliminate some potential symptoms, an endogenous inhibitory conditioned pain modulation system, that inhibits early nociceptive processing, can be properly activated. ${ }^{100}$ Therefore, when combining pain neuroscience education with dry needling, the concept of TrP-DN can be introduced during the educational part as one that primarily activates segmental or even brain-orchestrated top-down analgesic effects rather than having a local (ie, muscular) effect, and as one that should be integrated into a comprehensive pain management program. 
Third, it is also possible that needling therapies, particularly TrP-DN, act at some levels of the central nervous system (as it has been previously discussed), whereas pain neuroscience education in others. Therefore, combination of tissue-based interventions, such as TrP-DN (bottom-up techniques) should be combined with neuroscience pain education (top-down techniques). ${ }^{101}$ This hypothesis has been supported by a preliminary clinical trial showing that the application of TrP-DN was effective for improving pain, related-disability, kinesiophobia and widespread pressure pain sensitivity in individuals with mechanical low back pain, but the inclusion of a neuroscience education resulted in greater improvements in kinesiophobia. ${ }^{102}$ Both approaches should be considered complementary.

Some aspects not usually considered in TrP-DN literature include patient's expectations and beliefs, previous experiences and patient-clinician interaction. Expectancy can significantly influence the anticipation and experience of pain. ${ }^{103}$ In fact, anticipation ofpain may be related to the presence or development of fear ofneedles, an event easily found after previous negative experiences with needles. Further, the clinical context in which a painful intervention/ stimulus, ie, TrP-DN, is delivered, affects patients' experience and the triggered responses. ${ }^{104}$ Legrain et al showed that patients should be able to focus and maintain their attention on the processing of pain-information (pain neuroscience education) without being too centered/preoccupied by the nociceptive stimuli (needling intervention) ${ }^{105}$ In fact, anticipation of pain can increase the activity in the anterior cingulate cortex, ${ }^{106}$ a brain area also activated during TrP-DN ${ }^{83}$ which supports the needof reducing a potential anticipation of pain during needling interventions.

Fourth, another important topic to consider is the patientclinician interaction. In order to make the message provided during the combined application of pain neuroscience education and TrP-DN more consistent, clinicians should consider avoiding conflicting or contradictory messages during

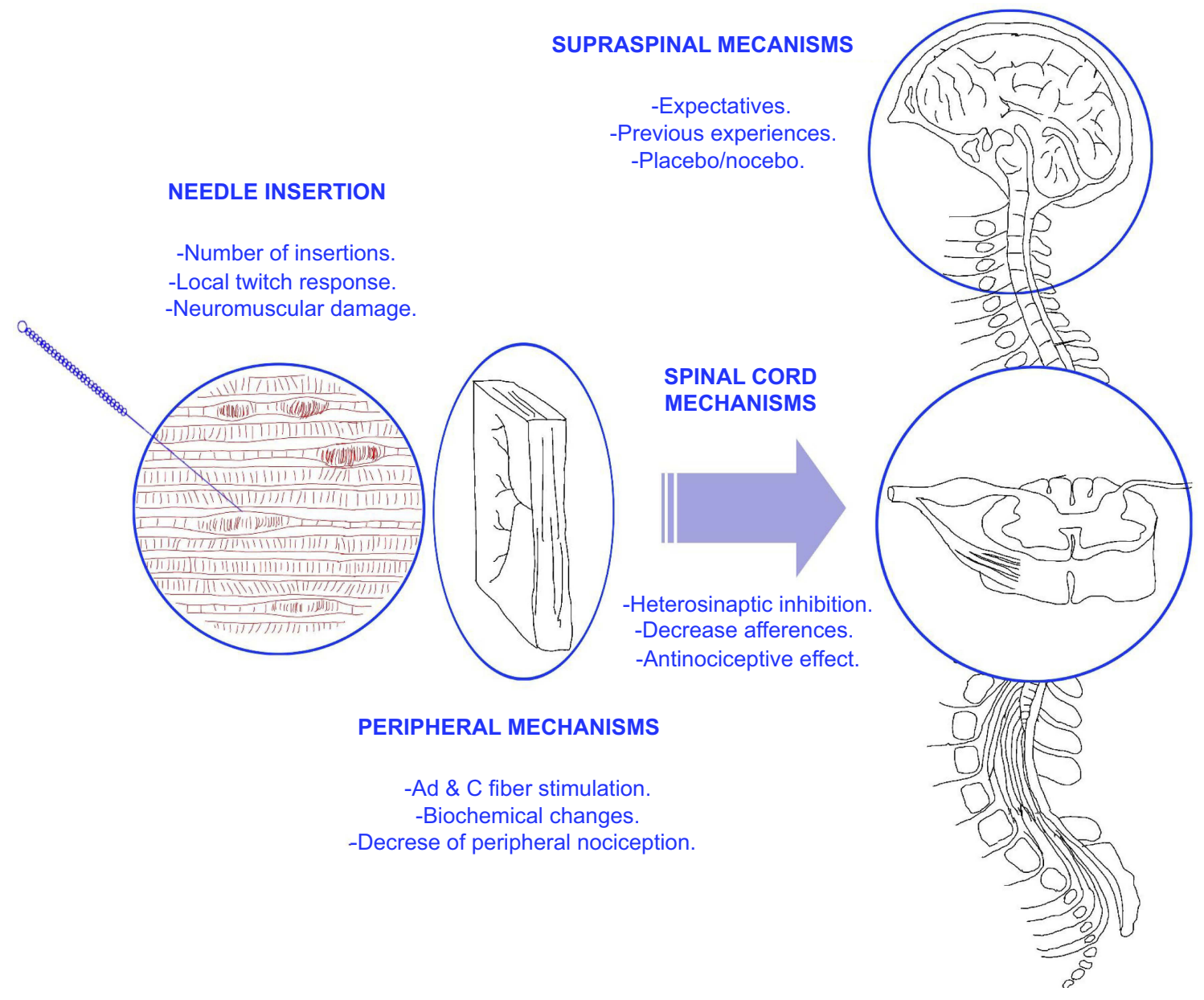

Figure I Proposed model explaining potential variables influencing neurophysiological mechanisms of trigger point dry needling. 
treatment. For instance, not using nocebo words during the treatment maybe particularly relevant. The use of words such as "pain during the technique", "painful technique", should be avoided by the clinician. Similarly, the use of positive words such as "effective treatment" could also influence patient's expectance but, if contrary to the results, may frustrate the patient. This is important since placebo analgesia recruits subcortical and opioid sensitive brain regions, eg, rostral anterior cingulate cortex, thalamus, insula, amygdala, also involved in pain perception and modulated by needling insertion. There is no study investigating these topics in relation to TrP-DN interventions.

Based on current discussion, we propose the following pain model for explaining the potential effects of dry needling integrating contemporary pain sciences (Figure 1). According to this model, some clinical factors modulated by the therapist, eg, number of needling insertions, number of local twitch responses obtained during the procedure, can influence the physiological effects of dry needling. This model integrates physiological effects of TrP-DN at the periphery, the spinal cord and the brainstem including those cognitive factors, eg, expectative, previous experiences, and therapist-patient interaction, ie, placebo or nocebo effect. All these factors interact in a complex neurophysiological reasoning for explaining the clinical effects of TrP-DN.

\section{Conclusion}

This narrative review presents current perspectives on the clinical application of trigger point dry needling for the management of chronic pain. Current evidence, mostly experimental studies, supports a possible role of myofascial trigger points in relation to the excitability of the central nervous system. The application of trigger point dry needling is able to reduce this excitability by reducing peripheral nociception from the trigger point, by reducing dorsal horn neuron activity, and by modulating brainstem areas. However, effects are only seen at short-term and effect sizes are small, pointing to a particular role that TrPs play within the complex chronic pain experience. There is no consensus on the clinical application of trigger point dry needling since some authors propose the need of eliciting local twitch responses during the needling intervention to be effective, whereas others do not. Finally, the application of trigger point dry needling should be integrated into a pain neuroscience paradigm by combining its application with pain neuroscience education, manual therapy and graded exercises. Future studies should investigate the effects of patient's expectation and patient-clinician interaction in the clinical outcomes of trigger point dry needling.

\section{Author contributions}

Both authors contributed to data analysis, drafting or revising the article, gave final approval of the version to be published, and agree to be accountable for all aspects of the work.

\section{Disclosure}

Dr Jo Nijs has co-authored a book for clinicians on pain neuroscience education, but the royalties for the book were collected by the Vrijie Universiteit Brussel and not him personally. Dr. Fernandez-de-las-Penas is an instructor in Trigger Point Therapy and also receive royalties from published books. The authors report no other conflicts of interest in this work.

\section{References}

1. Handwerker H, Arendt-Nielsen L. Pain Model: Translational Relevance and Applications. Seattle: IASP Press; 2013.

2. Simons DG, Travell JG, Simons L. Myofascial Pain and Dysfunction. The Trigger Point Manual. 3th ed. Philadelphia: Wolters Kluwer; 2019.

3. Fernández-de-Las-Peñas $\mathrm{C}$, Dommerholt J. International consensus on diagnostic criteria and clinical considerations of myofascial trigger points: a Delphi study. Pain Med. 2018;19:142-150. doi:10.1093/pm/ pnx207

4. Palacios-Ceña $\mathrm{M}$, Castaldo $\mathrm{M}$, Wang $\mathrm{K}$, et al. Relationship of active trigger points with related disability and anxiety in people with tension-type headache. Medicine. 2017;96:e6548. doi:10.1097/MD.0000000000006548

5. Ferracini GN, Florencio LL, Dach F, et al. Myofascial trigger points and migraine-related disability in women with episodic and chronic migraine. Clin J Pain. 2017;33:109-115. doi:10.1097/ AJP.0000000000000387

6. Fernández-de-Las-Peñas C, Galán-del-Río F, Alonso-Blanco C, Jiménez-García R, Arendt-Nielsen L, Svensson P. Referred pain from muscle trigger points in the masticatory and neck-shoulder musculature in women with temporomandibular disorders. J Pain. 2010;11:1295-1304. doi:10.1016/j.jpain.2010.03.005

7. Cerezo-Téllez E, Torres-Lacomba M, Mayoral-Del Moral O, Sánchez-Sánchez B, Dommerholt J, Gutiérrez-Ortega C. Prevalence of myofascial pain syndrome in chronic non -specific neck pain: a population-based cross-sectional descriptive study. Pain Med. 2016;17:2369-2377. doi:10.1093/pm/pnw114

8. Fernández-Pérez A, Villaverde-Gutiérrez C, Mora-Sánchez A, Alonso-Blanco $\mathrm{C}$, Sterling $\mathrm{M}$, Fernández-de-Las-Peñas C. Muscle trigger points, pressure pain threshold, and cervical range of motion in patients with high level of disability related to acute whiplash injury. $J$ Orthop Sports Phys Ther. 2012;42:634-641. doi:10.2519/jospt.2012.4117

9. Bron C, Dommerholt J, Stegenga B, Wensing M, Oostendorp RA. High prevalence of shoulder girdle muscles with myofascial trigger points in patients with shoulder pain. BMC Musculoskelet Disord. 2011;12:139. doi:10.1186/1471-2474-12-181

10. Fernández-Carnero J, Fernández-de-Las-Peñas $C$, de la LlaveRincón AI, Ge HY, Arendt-Nielsen L. Prevalence of and referred pain from myofascial trigger points in the forearm muscles in patients with lateral epicondylalgia. Clin J Pain. 2007;23(4):353360. doi:10.1097/AJP.0b013e31803b3785 
11. Iglesias-González JJ, Muñoz-García MT, Rodrigues-de-Souza DP, Alburquerque-Sendín F, Fernández-de-Las-Peñas C. Myofascial trigger points, pain, disability, and sleep quality in patients with chronic nonspecific low back pain. Pain Med. 2013;14:19641970. doi:10.1111/pme.12224

12. Chiarotto A, Clijsen R, Fernandez-de-Las-Peñas C, Barbero M. Prevalence of myofascial trigger points in spinal disorders: a systematic review and meta-analysis. Arch Phys Med Rehabil. 2016;97:316-337. doi:10.1016/j.apmr.2015.09.021

13. Shah JP, Phillips TM, Danoff JV, Gerber LH. An in vivo microanalytical technique for measuring the local biochemical milieu of human skeletal muscle. J Appl Physiol. 2005;99:1977-1984. doi:10.1152/japplphysiol.00419.2005

14. Shah JP, Danoff J, Desai M, et al. Biochemicals associated with pain and inflammation are elevated in sites near to and remote from active myofascial trigger points. Arch Phys Med Rehabil. 2008;89:16-23. doi:10.1016/j.apmr.2007.10.018

15. Shah JP, Gilliams EA. Uncovering the biochemical milieu of myofascial trigger points in vivo microdialysis: an application of muscle pain concepts to myofascial pain syndrome. $J$ Bodyw Mov Ther. 2008;12:371-384. doi:10.1016/j.jbmt.2008.06.006

16. Li LT, Ge HY, Yue S, Arendt-Nielsen L. Nociceptive and nonnociceptive hypersensitivity at latent myofascial trigger points. Clin J Pain. 2009;25:132-137. doi:10.1097/AJP.0b013e3181878f87

17. Wang YH, Ding $X$, Zhang $Y$ et al. Ischemic compression block attenuates mechanical hyperalgesia evoked from latent myofascial trigger point. Exp Brain Res. 2010;202:265-267. doi:10.1007/ s00221-009-2129-2

18. Kuan TS, Hong CZ, Chen JT, Chen SM, Chien CH. The spinal cord connections of the myofascial trigger spots. Eur J Pain. 2007;11:624-634. doi:10.1016/j.ejpain.2006.10.001

19. Xie P, Qin B, Song G, et al. Microstructural abnormalities were found in brain gray matter from patients with chronic myofascial pain. Front Neuroanat. 2016;10:122. doi:10.3389/ fnana.2016.00122

20. Lucas KR, Rich PA, Polus BI. Muscle activation patterns in the scapular positioning muscles during loaded scapular plane elevation: the effects of latent myofascial trigger points. Clin Biomech. 2010;25:765-770. doi:10.1016/j.clinbiomech.2010.05.006

21. Ge HY, Arendt-Nielsen L, Madeleine P. Accelerated muscle fatigability of latent myofascial trigger points in humans. Pain Med. 2012;13:957-964. doi:10.1111/j.1526-4637.2012.01416.x

22. Ibarra JM, Ge HY, Wang C, Martínez Vizcaíno V, Graven-Nielsen T, Arendt-Nielsen L. Latent myofascial trigger points are associated with an increased antagonistic muscle activity during agonist muscle contraction. J Pain. 2011;12:1282-1288. doi:10.1016/j.jpain.2011.09.005

23. Annaswamy TM, De Luigi AJ, O`Neill BJ, et al. Emerging concepts in the treatment of myofascial pain: a review of medications, modalities, and needle-based interventions. $P m R$. 2011;3:940-961. doi:10.1016/j.pmrj.2011.06.013

24. Dommerholt J, Fernandez-de-Las-Peñas C. Trigger Point Dry Needling: An Evidence and Clinical- Based Approach. 2th ed. London: Churchill Livingstone, Elsevier; 2019.

25. American Physical Therapy Association (APTA). Description of Dry Needling in Clinical Practice: An Educational Resource Paper. Virginia: APTA Public Policy P, and Professional Affairs Unit; 2013.

26. Autralian Society of Acupuncture Physiotherapists (ASAP). Guidelines for Safe Acupuncture and Dry Needling Practice. Wellington: Autralian Society of Acupuncture Physiotherapists (ASAP); 2014.

27. Hong C. Lidocaine injection versus dry needling to myofascial trigger point. The importance of the local twitch response. $A m J$ Phys Med Rehabil. 1994;73:256-263.
28. Fernández-Carnero J, Gilarranz-de-Frutos L, Leon-Hernandez JV, et al. Effectiveness of different deep dry needling dosages in the treatment of patients with cervical myofascial pain: a pilot RCT. Am J Phys Med Rehabil. 2017;96:726-733. doi:10.1097/ PHM.0000000000000733

29. Koppenhaver SL, Walker MJ, Rettig C, et al. The association between dry needling-induced twitch response and change in pain and muscle function in patients with low back pain: a quasiexperimental study. Physiotherapy. 2017;103:131-137. doi:10.1016/j.physio.2016.05.002

30. Perreault T, Dunning J, Butts R. The local twitch response during trigger point dry needling: is it necessary for successful outcomes?. J Bodyw Mov Ther. 2017;21:940-947. doi:10.1016/j. jbmt.2017.03.008

31. Poveda-Pagán EJ, Lozano-Quijada C, Segura-Heras JV, Peral-Berna M, Lumbreras B. Referred pain patterns of the infraspinatus muscle elicited by deep dry needling and manual palpation. J Altern Complement Med. 2017;23:890-896. doi:10.1089/acm.2016.0306

32. McEvoy J, Dommerholt J, Rice D, Holmes L, Grobli C, Fernández-de-Las-Penas C. Guidelines for Safe Dry Needling Practice for Chartered Physiotherapists. Dublin: Irish Society of Chartered Physiotherapist (ISCP); 2011.

33. Halle JS, Halle RJ. Pertinent dry needling considerations for minimizing adverse effects: part one. Int J Sports Phys Ther. 2016;11:651-662.

34. Halle JS, Halle RJ. Pertinent dry needling considerations for minimizing adverse effects: part two. Int $J$ Sports Phys Ther. 2016;11:810-819.

35. McCulloch M, Nachat A, Schwartz J, Casella-Gordon V, Cook J. Acupuncture safety in patients receiving antcoagulants: a systematic review. Perm J. 2015;19:68-73. doi:10.7812/TPP/14-057

36. Brady S, McEvoy J, Dommerholt J, Doody C. Adverse events following trigger point dry needling: a prospective survey of chartered physiotherapist. J Man Manip Ther. 2014;22:134-140. doi:10.1179/2042618613Y.0000000044

37. Hampton DA, Kaneko RT, Simeon E, Moren A, Rowell S, Watters JM. Acupuncture related pneumothorax. Med Acupunct. 2014;26:241-245. doi:10.1089/acu.2013.1022

38. Lee SW, Ahn JY, Choi WJ, et al. A needle penetrating the stomach cavity after acupuncture. Clin Endosc. 2014;47:258261. doi:10.5946/ce.2014.47.3.258

39. Chun KJ, Lee SG, Son BS. Kim Do H Life-threatening cardiac tamponade: a rare complication of acupuncture. $J$ Cardiothorac Surg. 2014;9:61. doi:10.1186/1749-8090-9-61

40. Lee JH, Lee H, Jo DJ. An acute cervical epidural hematoma as a complication of dry needling. Spine. 2011;36:E891-E893. doi:10.1097/BRS.0b013e3181fc1e38

41. Ji GY, Oh CH, Choi WS, Lee JB. Three cases of hemiplegia after cervical paraspinal muscle needling. Spine J. 2015;15:9-13. doi:10.1016/j.spinee.2014.11.007

42. Kim DC, Glenzer S, Johnson A, Nimityongskul P. Deep infection following dry needling in a young athlete: an underreported complication of an increasingly prevalent modality: A case report. J Bone Joint Surg. 2018;8:e73. doi:10.2106/JBJS.CC.18.00097

43. American Physical Therapy Association (APTA). Physical Therapists and the Performance of Dry Needling: An Educational Resource Paper. Virginia: APTA Public Policy P, and Professional Affairs Unit; 2012.

44. Martín-Pintado-Zugasti A, Mayoral Del Moral O, Rd G, Fernández-Carnero J. Post-needling soreness after myofascial trigger point dry needling: current status and future research. $J$ Bodyw Mov Ther. 2018;22:941-946. doi:10.1016/j. jbmt.2018.01.003 
45. Domingo A, Mayoral O, Monterde S, Santafe MM. Neuromuscular damage and repair after dry needling in mice. Evid Based Complement Alternat Med. 2013;2013:260806. doi:10.1155/2013/260806

46. Baraja-Vegas L, Martín-Rodríguez S, Piqueras-Sanchiz F, et al. Localization of muscle edema and changes on muscle contractility after dry needling of latent trigger points in the gastrocnemius muscle. Pain Med. 2019. doi:10.1093/pm/pny306

47. Martin-Pintado Zugasti A, Fernández-Carnero J, León-Hernández $\mathrm{JV}$, et al. Postneedling soreness and tenderness after different dosages of dry needling of an active myofascial trigger point in patients with neck pain: a randomised controlled trial. Pm $R$. 2018;1934-1482(18):30287-30289.

48. Martin-Pintado Zugasti A, Rodriguez-Fernandez AL, GarciaMuro F, et al. Effects of spray and stretch on postneedling soreness and sensitivity after dry needling of a latent myofascial trigger point. Arch Phys Med Rehabil. 2014;95:1925-1932. doi:10.1016/j.apmr.2014.05.021

49. Martin-Pintado-Zugasti A, Pecos-Martin D, Rodriguez-Fernandez AL, et al. Ischemic compression after dry needling of a latent myofascial trigger point reduces post-needling soreness intensity and duration. Pm R. 2015;7:1026-1034. doi:10.1016/j.pmrj.2015.03.021

50. Salom-Moreno J, Jimenez-Gomez L, Gomez-Ahufinger V, et al. Effects of low-load exercise on postneedling-induced pain after dry needling of active trigger point in individuals with subacromial pain syndrome. PMR. 2017;9:1208-1216. doi:10.1016/j.pmrj.2017.04.012

51. Lewit K. The needle effect in the relief of myofascial pain. Pain. 1979;6:83-90.

52. Ong J, Claydon LS. The effect of dry needling for myofascial trigger points in the neck and shoulders: a systematic review and meta-analysis. J Bodyw Mov Ther. 2014;18:390-398. doi:10.1016/j.jbmt.2013.11.009

53. Liu L, Huang QM, Liu QG, et al. Effectiveness of dry needling for myofascial trigger points associated with neck and shoulder pain: a systematic review and meta-analysis. Arch Phys Med Rehabil. 2015;96:944-955. doi:10.1016/j.apmr.2014.12.015

54. Canadian Agency for Drugs and Technologies in Health. Dry Needling and Injection for Musculoskeletal and Joint Disorders: A Review of the Clinical Effectiveness, Cost-Effectiveness, and Guidelines. Ottawa: Canadian Agency for Drugs and Technologies in Health; 2016.

55. Kietrys DM, Palombaro KM, Azzaretto E, et al. Effectiveness of dry needling for upper-quarter myofascial pain: a systematic review and meta-analysis. $J$ Orthop Sports Phys Ther 2013;43:620-634. doi:10.2519/jospt.2013.4668

56. Morihisa R, Eskew J, McNamara A, Young J. Dry needling in subjects with muscular trigger points in the lower quarter: A systematic review. Int J Sports Phys Ther. 2016;11:1-14.

57. Braithwaite FA, Walters JL, Li LSK, Moseley GL, Williams MT, McEvoy MP. Effectiveness and adequacy of blinding in the moderation of pain outcomes: systematic review and meta-analyses of dry needling trials. PeerJ. 2018;6:e5318. doi:10.7717/peerj.5318

58. Vier C, Almeida MB, Neves ML, Santos ARSD, Bracht MA. The effectiveness of dry needling for patients with orofacial pain associated with temporomandibular dysfunction: a systematic review and meta-analysis. Braz J Phys Ther. 2019;23:3-11.

59. France S, Bown J, Nowosilskyj M, Mott M, Rand S, Walters J. Evidence for the use of dry needling and physiotherapy in the management of cervicogenic or tension-type headache: a systematic review. Cephalalgia. 2014;34:994-1003. doi:10.1177/ 0333102414523847

60. Hall ML, Mackie AC, Ribeiro DC. Effects of dry needling trigger point therapy in the shoulder region on patients with upper extremity pain and dysfunction: a systematic review with metaanalysis. Physiotherapy. 2018;104:167-177. doi:10.1016/j. physio.2017.08.001
61. Hu HT, Gao H, Ma RJ, Zhao XF, Tian HF, Li L. Is dry needling effective for low back pain?: A systematic review and PRISMAcompliant meta-analysis. Medicine. 2018;97:e11225. doi:10.1097/ MD.0000000000011225

62. He C, Ma H. Effectiveness of trigger point dry needling for plantar heel pain: a meta-analysis of seven randomized controlled trials. J Pain Res. 2017;10:1933-1942. doi:10.2147/JPR.S141607

63. Gattie E, Cleland JA, Snodgrass S. The effectiveness of trigger point dry needling for musculoskeletal conditions by physical therapists: A systematic review and meta-analysis. J Orthop Sports Phys Ther. 2017;47:133-149. doi:10.2519/jospt.2017.7096

64. Arias-Buría JL, Fernández-de-Las-Peñas C, Palacios-Ceña M, Koppenhaver SL, Salom-Moreno J. Exercises and dry needling for subacromial pain syndrome: A randomized parallel-group trial. J Pain. 2017;18:11-18. doi:10.1016/j.jpain.2016.08.013

65. Arias-Buría JL, Martín-Saborido C, Cleland J, Koppenhaver SL, Plaza-Manzano G, Fernández-de-Las-Peñas C. Cost-effectiveness evaluation of the inclusion of dry needling into an exercise program for subacromial pain syndrome: evidence from a randomized clinical trial. Pain Med. 2018;19:2336-2347. doi:10.1093/ $\mathrm{pm} / \mathrm{pny} 021$

66. Espí-López GV, Serra-Añó $P$, Vicent-Ferrando $J$, et al. Effectiveness of inclusion of dry needling in a multimodal therapy program for patellofemoral pain: A randomized parallelgroup trial. J Orthop Sports Phys Ther. 2017;47:392-440. doi:10.2519/jospt.2017.7389

67. Sánchez-Romero EA, Pecos-Martín D, Calvo-Lobo C, OchoaSáez V, Burgos-Caballero V, Fernández-Carnero J. Effects of dry needling in an exercise program for older adults with knee osteoarthritis: A pilot clinical trial. Medicine. 2018;97:e11255. doi:10.1097/MD.0000000000011255

68. Dunning J, Butts R, Young I, et al. Periosteal electrical dry needling as an adjunct to exercise and manual therapy for knee osteoarthritis: a multicenter randomized clinical trial. Clin J Pain. 2018;34:1149-1158. doi:10.1097/AJP.0000000000000634

69. Cagnie B, Dewitte V, Barbe T, Timmermans F, Delrue N, Meeus M. Physiologic effects of dry needling. Curr Pain Headache Rep. 2013;17:348. doi:10.1007/s11916-013-0348-5

70. Gerwin RD, Dommerholt J, Shah JP. An expansion of Simons integrated hypothesis of trigger point formation. Curr Pain Headache Rep. 2004;8:468-475.

71. Chou LW, Hsieh YL, Kao MJ, Hong JZ. Remote influences of acupuncture on the pain intensity and the amplitude changes of endplate noise in the myofascial trigger point of the upper trapezius muscle. Arch Phys Med Rehabil. 2009;90:905-912. doi:10.1016/j.apmr.2008.12.020

72. Liu QG, Liu L, Huang QM, Nguyen TT, Ma YT, Zhao JM. Decreased spontaneous electrical activity and acetylcholine at myofascial trigger spots after dry needling treatment: A pilot study. Evid Based Complement Alternat Med. 2017;2017:3938191. doi:10.1155/2017/3938191

73. Abbaszadeh-Amirdehi M, Ansari NN, Naghdi S, Olyaei G, Nourbakhsh MR. Therapeutic effects of dry needling in patients with upper trapezius myofascial trigger points. Acupunct Med. 2017;35:85-92. doi:10.1136/acupmed-2016-011082

74. Abbaszadeh-Amirdehi ANN, Naghdi S. Nourbakhsh. Neurophysiological and clinical effects of dry needling in patients with upper trapezius myofascial trigger points. MR. J Bodyw Mov Ther. 2017;21:48-52. doi:10.1016/j.jbmt.2016.04.014

75. Cagnie B, Barbe T, De Ridder E, Van Oosterwijck J, Cools A, Danneels L. The influence of dry needling of the trapezius muscle on muscle blood flow and oxygenation. J Manipulative Physiol Ther. 2012;35:685-691. doi:10.1016/j.jmpt.2012.10.005

76. Dommerholt J. Dry needling: peripheral and central considerations. J Manual Manipul Ther. 2011;19:223-237. doi:10.1179/ $106698111 X 13129729552065$ 
77. Butts R, Dunning J, Perreault T, Mourad F, Grubb M. Peripheral and spinal mechanisms of pain and dry needling mediated analgesia: A clinical resource guide for health care professionals. Int $J$ Phys Med Rehabil. 2016;4:2. doi:10.4172/2329-9096.1000327

78. Chou LW, Kao MJ, Lin JG. Probable mechanisms of needling therapies for myofascial pain control. Evid Based Complement Alternat Med. 2012;2012:705327. doi:10.1155/2012/705327

79. Hsieh YL, Yang SA, Yang CC, Chou LW. Dry needling at myofascial trigger spots of rabbit skeletal muscles modulates the biochemicals associated with pain, inflammation, and hypoxia. Evid Based Complement Alternat Med. 2012;2012:342165. doi:10.1155/2012/342165

80. Hsieh YL, Kao MJ, Kuan TS, Chen SM, Chen JT, Hong CZ. Dry needling to a key myofascial trigger point may reduce the irritability of satellite MTrPs. Am J Phys Med Rehabil. 2007;86:397403. doi:10.1097/PHM.0b013e31804a554d

81. Tsai CT, Hsieh LF, Kuan TS, Kao MJ, Chou LW, Hong CZ. Remote effects of dry needling on the irritability of the myofascial trigger point in the upper trapezius muscle. Am J Phys Med Rehabil. 2010;89:133-140. doi:10.1097/PHM.0b013e3181a5b1bc

82. Hsieh YL, Chou LW, Joe YS, Hong CZ. Spinal cord mechanism involving the remote effects of dry needling on the irritability of myofascial trigger spots in rabbit skeletal muscle. Arch Phys Med Rehabil. 2011;92:1098-1105. doi:10.1016/j.apmr.2010.11.018

83. Hsieh YL, Yang SA, Liu SY, Chou LW, Honc CZ. Remote dosedependent effects of dry needling at distant myofascial trigger spots of rabbit skeletal muscles on reduction of substance P levels of proximal muscle and spinal cords. Biomed Res Int. 2014;2014:982121. doi:10.1155/2014/982121

84. Srbely JZ, Dickey JP, Lee D, Lowerison M. Dry needle stimulation of myofascial trigger points evokes segmental anti-nociceptive effects. J Rehabil Med. 2010;42:463-468. doi:10.2340/ 16501977-0535

85. Audette JF, Wang F, Smith H. Bilateral activation of motor unit potentials with unilateral needle stimulation of active myofascial trigger points. Am J Phys Med Rehabil. 2004;83:368-374.

86. Chae Y, Chang DS, Lee SH, et al. Inserting needles into the body: a meta-analysis of brain activity associated with acupuncture needle stimulation. J Pain. 2013;14:215-222. doi:10.1016/j. jpain.2012.11.011

87. Niddam DM, Chan RC, Lee SH, Yeh TC, Hsieh JC. Central modulation of pain evoked from myofascial trigger point. Clin $J$ Pain. 2007;23:440-448. doi:10.1097/AJP.0b013e318058accb

88. Louw A, Zimney K, Puentedura EJ, Diener I. The efficacy of pain neuroscience education on musculoskeletal pain: a systematic review of the literature. Physiother Theory Pract. 2016;32:332355. doi:10.1080/09593985.2016.1194646

89. Geneen LJ, Moore RA, Clarke C, Martin D, Colvin LA, Smith BH. Physical activity and exercise for chronic pain in adults: an overview of cochrane reviews. Cochrane Database Syst Rev. 2017;4:CD011279.

90. Brunner E, De Herdt A, Minguet P, Baldew SS, Probst M. Can cognitive behavioural therapy-based strategies be integrated into physiotherapy for the prevention of chronic low back pain? A systematic review. Dis Rehabil. 2013;35:1-10. doi:10.3109/ 09638288.2012.683848
91. Williams AC, Eccleston C, Morley S. Psychological therapies for the management of chronic pain (excluding headache) in adults. Cochrane Database Syst Rev. 2012;11:CD007407.

92. Nijs J, Mairesse O, Neu D, et al. Sleep disturbances in chronic pain: neurobiology, assessment and treatment in physical therapist practice. Phys Ther. 2018;98:325-335. doi:10.1093/ptj/pzy020

93. Lluch Girbes E, Meeus M, Baert I, Balancing NJ. "hands-on" with "hands-off" physical therapy interventions for the treatment of central sensitization pain in osteoarthritis. Man Ther. 2015;20:349-352. doi:10.1016/j.math.2014.07.017

94. Woolf CJ. Central sensitization: implications for the diagnosis and treatment of pain. Pain. 2011;152:S2-15. doi:10.1016/j. pain.2010.09.030

95. Kosek E, Cohen M, Baron R, et al. Do we need a third mechanistic descriptor for chronic pain states? Pain. 2016;157:13821386. doi:10.1097/j.pain.0000000000000507

96. Fernández-de-Las-Peñas C, Dommerholt J. Myofascial trigger points: peripheral or central phenomenon? Curr Rheumatol Rep. 2014;16:395. doi:10.1007/s11926-013-0395-2

97. Malfliet A, Kregel J, Coppieters I, et al. Effect of pain neuroscience education combined with cognition-targeted motor control training on chronic spinal pain: A randomized clinical trial. JAMA Neurol. 2018;75:808-817. doi:10.1001/ jamaneurol.2018.0492

98. Fernández-de-Las Peñas C, Ortega-Santiago R, de la LlaveRincón AI, et al. Manual physical therapy versus surgery for carpal tunnel syndrome: A randomized parallel-group trial. $J$ Pain. 2015;16:1087-1094. doi:10.1016/j.jpain.2015.07.012

99. Legrain V, Iannetti GD, Plaghki L, Mouraux A. The pain matrix reloaded: a salience detection system for the body. Prog Neurobiol. 2011;93:111-124. doi:10.1016/j.pneurobio.2010.10.005

100. Bjorkedal E, Flaten MA. Expectations of increased and decreased pain explains the effect of conditioned pain modulation in females. J Pain Res. 2012;5:289-300. doi:10.2147/JPR.S33559

101. Louw A, Nijs J, Puentedura EJ. A clinical perspective on a pain neuroscience education approach to manual therapy. J Man Manip Ther. 2017;25:160-168. doi:10.1080/10669817.2017.1323699

102. Téllez-García M, de-la- Llave-Rincón AI, Salom-Moreno J, Palacios-Ceña M, Ortega-Santiago R, Fernández-de-Las-Peñas C. Neuroscience education in addition to trigger point dry needling for the management of patients with mechanical chronic low back pain: a preliminary clinical trial. J Bodyw Mov Ther. 2015;19:464-472. doi:10.1016/j.jbmt.2014.11.012

103. Wager TD, Rilling JK, Smith E, et al. Placebo-induced changes in FMRI in the anticipation and experience of pain. Science. 2004;303:11621167. doi:10.1126/science. 1093065

104. Moseley GL, Arntz A. The context of a noxious stimulus affects the pain it evokes. Pain. 2007;133:64-71. doi:10.1016/j. pain.2007.03.002

105. Legrain V, Crombez G, Verhoeven K, Mouraux A. The role of working memory in the attentional control of pain. Pain. 2011;152:453-459. doi:10.1016/j.pain.2010.11.024

106. Longo MR, Iannetti GD, Mancini F, Driver J, Haggard P. Linking pain and the body: neural correlates of visually induced analgesia. J Neurosci. 2012;32:2601-2607. doi:10.1523/JNEUROSCI.403111.2012 


\section{Publish your work in this journal}

The Journal of Pain Research is an international, peer reviewed, open access, online journal that welcomes laboratory and clinical findings in the fields of pain research and the prevention and management of pain Original research, reviews, symposium reports, hypothesis formation and commentaries are all considered for publication. The manuscript management system is completely online and includes a very quick and fair peer-review system, which is all easy to use. Visit http:// www.dovepress.com/testimonials.php to read real quotes from published authors.

Submit your manuscript here: https://www.dovepress.com/journal-of-pain-research-journal 